\title{
Medical Equipment Maintenance under Modernized Management
}

\author{
Hongjie Gao \\ People's Hospital of Zhengzhou, Zhengzhou City, P.R. China \\ tuke126@126.com
}

Corresponding author: Hongjie Gao

\begin{abstract}
In order to realize the health run smoothly for modern hospital, it must strengthen the maintenance of medical equipment management. The degree of precision instrument reflected the hospital diagnosis and treatment level and ability. Through the study of the modernization of hospital medical equipment maintenance management, this study achieve the goal of construction of modern hospital. The normal operation of the large medical equipment ensured the normal operation of the hospital work. This article mainly expounded the present situation of comprehensive hospital medical equipment maintenance management, the footprints were put forward based on the present situation of hospital medical equipment maintenance management measures to modernize.
\end{abstract}

Keywords: hospital medical apparatus and instruments; maintenance; modern management.

\section{Introduction}

The establishment of hospital was based on the medical apparatus and instruments. The comprehensive grasp of the advantage and disadvantages of modern medical instrument promoted the progress of the hospital diagnosis and treatment. More and more medical device types of development unceasingly made most of the hospital medical equipment maintenance management work face unprecedented challenges. How to realize the modernization of medical equipment management at present hospital management was an urgent need to solve the problem.

\section{Present situation of the comprehensive hospital medical equipment maintenance management}

\subsection{Lack of a sound modern maintenance management system}

At present, the comprehensive hospital management system had been relatively perfect [1]. In the management of medical equipment, it still did not reach the designated position, the lack of sound modern maintenance management system. It was a blind area in hospital management. Hospital of the existing management system cannot meet the demand of modern medical equipment maintenance. Most hospital rules did not explicitly specific maintenance management system, made maintenance personnel appear the situation of division of labor. Generally, the repair of medical equipment were relying on agent or manufacturers. Companies could increase the maintenance cost due to the rich experience in maintenance, which had no doubt give the hospital increased cost burden.

In recent years, with the increased number of medical equipment, medical apparatus and instruments of the quality problem was becoming more and more obvious, many hospital in the medical equipment maintenance management of relatively backward technology. There was no clear system of maintenance and method need to be improved, with the constant improvement of the medical equipment automation. The maintenance personnel quality and technology level also need to be improved, the maintenance management need to implement modern management methods. The hospital actually had many difficulties in personnel, system and methods. The lack of modern maintenance management system affected the equipment maintenance management of hospital in China, thus affected the hospital diagnosis and treatment work.

\subsection{Lack of advanced maintenance method}

In recent years, more and more kinds of medical equipment was constantly be invented, and make the most hospital unable perform well the maintenance management of new equipment. Modern medical equipment maintenance management required the maintenance staff have high technology 
qualification, advanced tools, and maintenance method in order to promote the hospital medical equipment management to modern management [2]. Most hospital in our country were lack advanced repair method, not only affect hospital medical equipment maintenance management, but also affected the hospital actual economic benefits. Studies showed that the cause of hospital maintenance methods lagged behind was the due to the lack of repair mechanism hospital senior equipment investment, and professional maintenance staff was not high, skill was to single, narrow range of knowledge, severely restrict the development of hospital medical equipment maintenance management.

\section{3 low hospital recognition degree and low quality of maintenance personnel}

For medical equipment maintenance management, many hospital had not give highly attention. Comprehensive hospital were lack of high talented maintenance. While, the management of small hospital maintenance personnel were insufficient, and lack of basic access to maintenance personnel qualifications, etc. There were no clear regulation for maintenance personnel occupation entrance.

\section{Modern management measures of comprehensive hospital equipment maintenance}

\subsection{To build digital management platform of medical device industry}

The management of hospital medical equipment maintenance was a pretty tedious work, which not only classified each equipment registration, but also timely record instrument malfunction, causes, solutions, repairs and maintenance personnel, etc. These records information constituted the basic technical files of equipment. Through the study of the track record of medical apparatus and instruments, and provided a reference for solving similar problems in the future. Through the construction of medical digital management platform, enabled the hospital staff to use medical equipment maintenance management system, fully grasp the information of the equipment. Hospital medical equipment management platform digital diagram was shown in figure 1.

Figure 1. Medical instrument digital management platform

\begin{tabular}{|c|c|c|c|}
\hline \multirow{11}{*}{$\begin{array}{c}\text { Medical } \\
\text { instrument } \\
\text { digital } \\
\text { management } \\
\text { platform }\end{array}$} & $\begin{array}{c}\text { Purchase } \\
\text { entrance } \\
\text { access }\end{array}$ & \multicolumn{2}{|c|}{$\begin{array}{l}\text { Clinical requirement, online purchase application, technology } \\
\text { assessment, installation and acceptance }\end{array}$} \\
\hline & $\begin{array}{c}\text { Asset } \\
\text { management }\end{array}$ & \multicolumn{2}{|c|}{ Asset card recruit, asset transfer, delivery, depreciation, scrap } \\
\hline & \multirow{6}{*}{$\begin{array}{c}\text { Quality } \\
\text { management }\end{array}$} & Risk assessment & Evaluation model and quantitative indicators \\
\hline & & $\begin{array}{c}\text { Preventive } \\
\text { maintenance }\end{array}$ & PM plan, steps, frequency and content \\
\hline & & Maintenance & $\begin{array}{l}\text { Online maintenance application, electronic } \\
\text { documents, dynamic query }\end{array}$ \\
\hline & & $\begin{array}{c}\text { Quality } \\
\text { inspection }\end{array}$ & $\begin{array}{l}\text { Electrical performance test and the } \\
\text { informationization process }\end{array}$ \\
\hline & & measurement & $\begin{array}{l}\text { Electronic records of measurement process and } \\
\text { results }\end{array}$ \\
\hline & & Train & Basic principle, safely usage, simple maintenance \\
\hline & \multirow{3}{*}{$\begin{array}{l}\text { Analysis of } \\
\text { evaluation }\end{array}$} & $\begin{array}{c}\text { Statistical } \\
\text { quality }\end{array}$ & PM or repair report, workload statistics, etc \\
\hline & & Benefit analysis & Cost analysis, economic and social benefits \\
\hline & & Clinical analysis & $\begin{array}{l}\text { Diagnosis and treatment equipment associated } \\
\text { analysis }\end{array}$ \\
\hline
\end{tabular}

Through this system, the maintenance personnel could gain the equipment user's feedback information, and improve the efficiency of hospital medical equipment maintenance management work according to these feedback timely maintenance of processing. In the digital management 
platform, relevant staff could build equipment basic parameter database and the establishment of a systematic equipment maintenance records, make maintenance personnel repair the equipment with the guidance of these maintenance records of maintenance process, which could significantly improve the work efficiency of the maintenance staff, also reduce the maintenance expenditure of hospital. The digital classification management of maintenance records enabled the hospital staff had a comprehensive understanding from the Internet to the specific usage of equipment, help to find problems in time and deal with the problem.

\subsection{To ameliorate medical equipment maintenance management system}

The amelioration of related equipment maintenance management system could be the first step for comprehensive hospital medical equipment maintenance management. First of all, the improvement of the system for hospital medical equipment maintenance personnel recruit increased participation in the threshold of the maintenance work. The competitive mechanism could fully activate the enthusiasm of maintenance personnel work, it still should improve the system of equipment maintenance, reasonable division of labor, maintenance personnel. For large equipment, it should be handled by special maintenance personnel for routine maintenance. In the management system of medical devices, it should strengthen and clear the details of the rules for maintenance personnel responsibility and leadership responsibility system, accident responsibility system, maintenance management and maintenance for ensuring adequate funding for sale, its management of archives management, and other ingredients play to the rule of the technical personnel, reduce the maintenance cost for hospital to obtain the maximum economic benefit. The improvement of equipment maintenance quality could improve the diagnosis and treatment of hospital work. Generally, the manager responsibility should be determined and formulated by the medical equipment maintenance management system and reasonable division management. Under the guidance of perfect maintenance management system, the leadership should establish the competent maintenance agency spending plan, and the relevant technical personnel to carry on the comprehensive maintenance service, improve the quality of hospital medical equipment maintenance and speed. Perform a good job of maintenance management of medical apparatus and instruments could maximum limit to extend the service life of equipment.

\subsection{Innovative equipment maintenance method}

In the modernization of hospital medical equipment maintenance management should also pay attention to the modernization of maintenance methods. At present, in the field of hospital medical equipment maintenance management in China was not enough, and it need improve the methods of maintenance management, speed up the modernization of hospital. Whether the equipment maintenance management work could perform well determined the level of the hospital scientific research and technology. The amelioration strengthening of equipment maintenance methods and improvement method of maintenance could improve the efficiency of medical equipment maintenance management. The advanced maintenance not only could reduce the management expenditure and personnel expenditure of the hospital, but also could maximize the shorten delay time of equipment malfunction. Through the advanced maintenance methods, the maintenance personnel could do a good job of maintenance equipment in time and ensure the hospital diagnosis and treatment work smoothly. It also need to formulate relevant appraisal and rewards and punishment system, in order to monitor maintenance personnel maintenance management, and reform the innovation to promote the equipment maintenance methods.

\section{Conclusion}

To sum up, in the management of medical equipment maintenance modernization, it need continuously improve the medical service responsibility consciousness and maintenance skills of maintenance personnel, and contribute to the further development of hospital. The well-performed medical equipment maintenance not only could improve the level of hospital diagnosis and treatment, but also could reduce the maintenance expenditure for the hospital and increase the hospital's social and economic benefits. The scientific and reasonable measures should be employed to optimize the 
maintenance of medical equipment, and continuously improve the level of hospital modernization management and promote the further development of Chinese medicine.

\section{References}

[1] C.L. Chen. The modernization of hospital medical equipment maintenance management, China Health Care \& Nutrition, vol, 18, pp.103-105, 2012.

[2] G.P. Yuan. Brief theory of the modern hospital medical equipment maintenance management, Harbin Medical Journal, vol.7, pp.201-211, 2012. 